\title{
La presencia del Glifo Emblema del murciélago en El Petén y el sur de Campeche y sus implicaciones políticas
}

\author{
The Presence of the Bat Emblem Glyph in The Petén \\ and Southern Campeche, and its Political Implications
}

\author{
Rogelio Valencia Rivera \\ Universidad Veracruzana \\ Octavio Q. Esparza Olguín \\ Centro de Estudios Mayas, \\ Instituto de Investigaciones Filológicas, \\ Universidad Nacional Autónoma de México
}

\begin{abstract}
ResUmen: En este trabajo se evalúan algunas hipótesis respecto al origen y la presencia del Glifo Emblema del murciélago en diversos sitios del sur de Campeche y El Petén guatemalteco, sobre todo a la luz de las evidencias encontradas en la Escalera Jeroglífica del Grupo Guzmán de El Palmar, donde dicho glifo aparece en relación con el sitio de Copán. Siendo que, hasta el momento, es la única mención directa a Copán en las inscripciones del sur de Campeche, cabe preguntarse si los ejemplos que aparecen del Glifo Emblema del murciélago en esta región estarían todos relacionados con Copán o si, por el contrario, resulta probable la existencia de más de un Glifo Emblema del murciélago operando durante el período Clásico en El Petén, especialmente en el Clásico Temprano. Su presencia en el sitio de Calakmul, de manera simultánea con el de los señores de Chatahn (Chatahn Winik), nos permite inferir que ambos grupos pudieron detentar el poder hasta la aparición del grupo que utilizaba el Glifo Emblema de la serpiente. Más tarde, dicho poder pudo haber sido compartido, tomando los señores de Chatahn una posición de subordinación respecto a los señores de Kaanu'l y hasta con los del grupo del Glifo Emblema del murciélago, pues existe evidencia del uso de ambos glifos de manera tardía dentro de Calakmul. En este caso, estamos ante un escenario donde diversos grupos no hegemónicos pudieron haber compartido el poder en ciertos sitios, para más adelante dar paso a dinastías que lo detentaban de forma única. Dichas dinastías no desdeñaban la herencia de ciertos grupos de prestigio subordinados al grupo de mayor hegemonía, dando lugar a la aparición de Glifos Emblema dobles, o compartidos, como es el caso de Yaxchilán, o el de Calakmul, donde ciertos nobles mantenían sus lazos de origen con la dinastía de los Chatahn Winik o la del murciélago, pese a vivir en un sitio gobernado por los señores de Kaanu'l.
\end{abstract}

Palabras clave: Glifo Emblema del murciélago, Chatahn Winik, Calakmul, El Palmar, Kaanu’l, Copán.

ABstract: This paper tries to explain the origin of the use of Emblem Glyphs that coexist simultaneously in the same site. We analyze the presence of the Bat Emblem 
Glyph in the Central Peten with a special emphasis on the most recent examples found at the site of El Palmar. We conclude that not all of the existing examples of this glyph could be situated under the sphere of Copan. So there must have been more than one bat glyph being used during the Early Classic in this area. The early presence of this glyph along with the one of the Chatahn Winik in Calakmul, lets us infer that both groups must have had some power at the beginning of the history of this site, until the Snake group appeared there, and took it over. Later on, power must have been shared by all of these three groups, with the Chatahn and Bat ones being subordinated to the Snake lords, as we can see some nobles tracing back their origin to both dynasties under the aegis of the snake lords. This brings up the discussion of the possibility that different groups on nobles might have shared the power during the early times of the Maya civilization, until the appearance of hegemonic groups. These hegemonic groups, even while holding the power, stated their relationship to the other origins of the nobility of the site. This shows up through the use of different Emblem Glyphs at the same time, at the same site, such as happened at Yaxchilán, or at Calakmul, where the lords used two Emblem Glyphs in many inscriptions.

KeYwords: Bat Emblem Glyph, Chatahn Winik, Calakmul, El Palmar, Kaanu’l, Copán.

RECEPCIÓN: 26 de octubre de 2016.

ACEPTACIÓN: 7 de febrero de 2017.

DOI: 10.19130/iifl.ecm.2018.51.868

\section{Introducción}

En el presente estudio evaluamos la posibilidad de que el Glifo Emblema ${ }^{1}$ (en adelante GE) del murciélago (Figura 1), asociado al sitio de Copán, haya tenido una presencia significativa en el Petén Central. Las características gráficas de este GE en Copán presentan el diseño de un signo con forma de cabeza de murciélago, en la mayoría de las ocasiones parecida a la variante del jeroglifo T756d del afamado catálogo de Thompson (1962). Dicha variante se encuentra complementada por una serie de afijos, entre los que se encuentra el silabograma pi, como en las Estelas A o I (Figura 1a), o bien, el fonograma pu, como en la Estela 8 (Figura 1c), existiendo ejemplos donde se encuentran representadas ambas sílabas, como es el caso de la Estela Papagayo (Figura 1d). Además, suele presentar los signos iconográficos de piedra colocados en la cabeza (Figura 1c), o en el cuerpo, en el caso de tratarse de un jeroglifo de figura completa y, en algunos pocos

\footnotetext{
${ }^{1}$ Si bien el empleo de la palabra "glifo" no resulta correcta desde el punto de vista de los estudios de gramatología (Pope, 1999: 216), la expresión "Glifo Emblema” ha sido utilizada desde que fuera inventada por Berlin (1958) para nombrar a un grupo de jeroglifos que parecían designar lugares, pero al no estar seguro de si lo que designaban eran familias, ciudades, casas dinásticas o topónimos, decidió emplear el término neutral "emblema". Debido a su uso tradicionalmente aceptado en los estudios de cultura y escritura maya, lo utilizaremos en este estudio.
} 
casos, signos de noche en la nariz o en la mejilla (Figura 1d). Estos elementos iconográficos empleados para señalar ciertas características de materialidad del logograma sobre el que son colocados, como el que el sustantivo que se nombra esté hecho de piedra o de madera, o en el caso de los elementos de noche y obscuridad que se añaden a los animales nocturnos, fueron denominados como property qualifiers ("calificadores de atributos") por Stone y Zender (2011: 13).
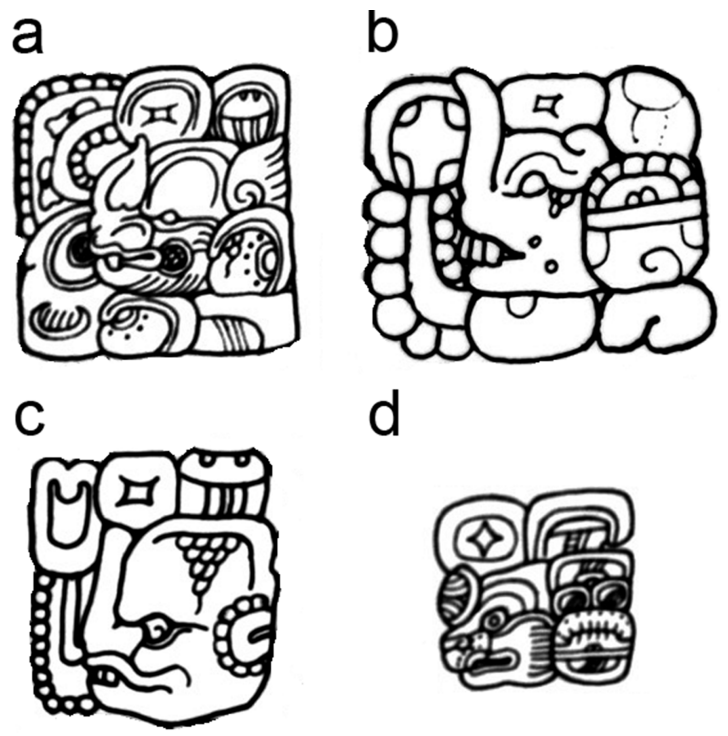

Figura 1. Ejemplos del Glifo Emblema del murciélago tal y como aparecen en Copán, a) Estela I, b) Estela 11, c) Estela 8 y d) Estela Papagayo.

Dibujos de Linda Schele, <http://research.famsi.org/schele.html >.

De 45 ejemplos del GE registrados en monumentos de Copán y de Quiriguá (ver Apéndice 1), 17 utilizan la cabeza del murciélago, o su cuerpo, con signos iconográficos de piedra; en otros 18 ejemplos además de los signos iconográficos de piedra se incluye el sufijo -pi; en un caso aparecen los signos iconográficos de piedra y el sufijo -pu; en otros seis la cabeza del murciélago aparece sin los signos iconográficos de piedra pero con complementos en -pi o en -pu, o ambos, y solamente hay tres ejemplos sin ninguno de estos atributos. Es decir, de los 45 ejemplos analizados, 42 presentan como características principales la presencia de los signos iconográficos de piedra y/o un sufijo (-pi o-pu), lo cual representa un $93 \%$ de los casos. De tres casos remanentes, uno muestra cierto grado de erosión (Banqueta Estructura 9N-158), otro es muy temprano (Estela Xukpí) y el otro procede de una región muy alejada del área maya (Vasija de Tazumal, Card y Zender, 2016). En los ejemplos en los que aparece el murciélago con los signos diagnósticos del logograma piedra cabría la posibilidad de que esto se debiera a una incorporación del silabograma -pi-, pero hemos visto que en un buen número 
de ejemplos aparecen ambos atributos del GE, por lo que ambas características son independientes.

Asimismo, el signo consistente en la cabeza de un murciélago puede actuar de tres maneras diferentes dentro de la escritura maya. Una es como logograma, con el significado de suutz', 'murciélago'. En este caso, el signo gráfico de la cabeza del quiróptero suele llevar elementos iconográficos del signo AK'AB', "noche, obscuridad", colocado debajo de la oreja o en la nariz, lo cual tiene que ver con los hábitos nocturnos de estos animales (Stone y Zender, 2011: 13). Existen otras dos formas en las que se emplea, pero esta vez como silabograma, la primera es como la sílaba -tz'i-, y la segunda como la sílaba -xu-. En el primer caso se presenta la cabeza sin elemento adicional alguno y, en la segunda, se suele presentar con elementos iconográficos relacionados con la noche, igual que para el logograma SUTZ'. Por lo tanto, los valores de lectura para este signo pueden ser suutz', $t z$ 'i o $x u$.

Este mismo jeroglifo de la cabeza del murciélago con características iconográficas de piedra aparece en Calakmul, sin sufijo adicional alguno y fuera del contexto de un GE, lo cual podría significar que en realidad esta combinación podría representar un logograma completo cuyo valor de lectura desconocemos. Dicho ejemplo se localiza en el tercer cuerpo de la esquina NO-N3 de la Estructura Sub 1-4 (Carrasco y Cordeiro, 2012) de la Acrópolis de Chi'k Naahb' (Figura 2).
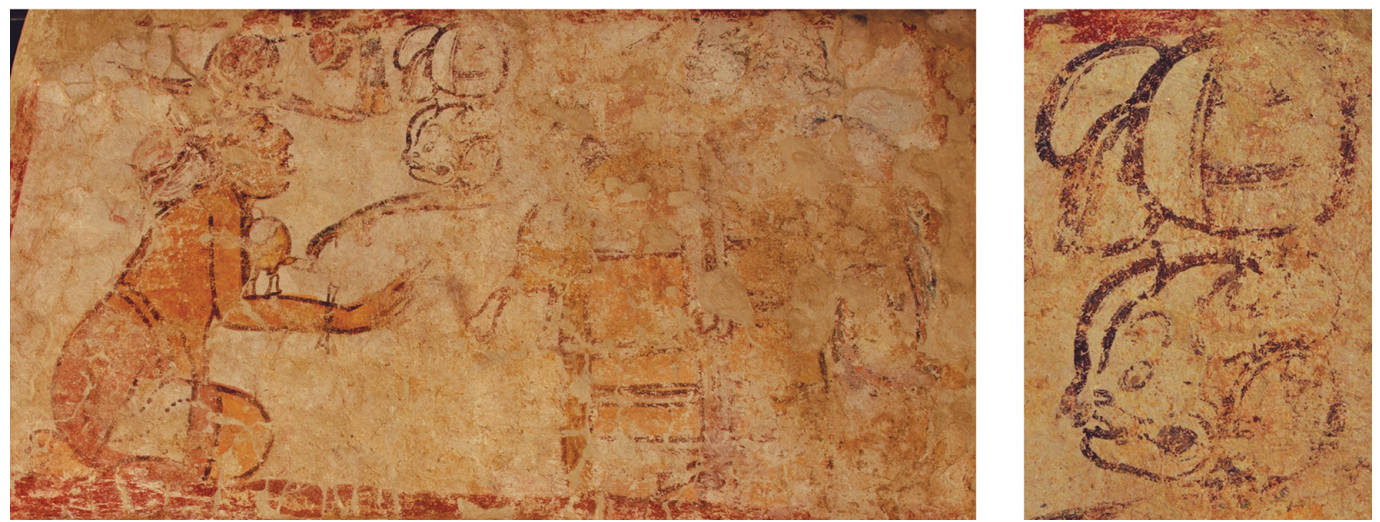

Figura 2. Ejemplo de un jeroglifo similar al que aparece en el GE de Copán, con la cabeza de un murciélago con el signo TUN infijo, localizado en la Estructura Sub 1-4 de la Acrópolis de Chi'k Naahb' del sitio arqueológico de Calakmul. Fotografía de Rogelio Valencia, con la autorización del Proyecto Arqueológico de Calakmul.

Para el caso del GE de Copán, cabe la posibilidad de que represente cualquiera de estos signos, pero debido a lo restringido de su uso y a una nueva aparición de este mismo signo en Calakmul, sin sufijo externo alguno y fuera del contexto de un GE, nos inclinamos por la idea de que en realidad se trata de un logograma completo. 
En conclusión, si bien es cierto que actualmente se conoce el valor fonético de algunos de los grafemas que componen el GE de Copán, no se ha llegado a un consenso sobre su lectura, pero podemos concluir que la presencia de los elementos iconográficos de piedra y/o los sufijos silábicos en -pi y en -pu, dentro del contexto adecuado, podrían indicarnos la presencia de este GE con un alto grado de probabilidad.

Es Heinrich Berlin (1958: 117) quien relaciona el signo del murciélago con la ciudad de Copán: "Copán, su emblema es la cara del murciélago, Zotz, con un Cauac en la región de la oreja; casi siempre lleva además de lo anterior un sufijo o postfijo a modo de dos ganchos". La cabeza del quiróptero fue empleada para formar otro GE el de un sitio aún no localizado, cercano a Copán y que aparece mencionado en inscripciones de este último sitio y de Quiriguá (Looper, 2007), pero en el caso de dicho GE, el signo del murciélago va siempre sufijado por el signo silábico -ya. También en Quiriguá aparecen menciones a otro lugar prefijado por el logograma IK', 'negro', más la cabeza del murciélago con elementos iconográficos de piedra y con sufijos en -la, -ya y -wa, pero no en relación a personajes históricos de Copán.

\section{La presencia del GE del murciélago en El Petén}

Un cartucho jeroglífico con características similares a las del GE de Copán fue hallado en algunos monumentos de Oxpemul, específicamente en tres de ellos. En la Estela 2, fechada para el año 771 d.C., ocupa el segundo cartucho, de arriba hacia abajo de la inscripción del costado izquierdo (Grube, 2005; Robichaux y Pruett, 2005). Aparece como título de un nombre personal, pero debido al estado de la inscripción es imposible saber si es un personaje local o un visitante. En la fotografía es muy difícil distinguir la presencia del murciélago debido al avanzado estado de erosión de la piedra sobre la que se labró la inscripción.

El otro monumento donde aparece el GE del murciélago en Oxpemul es el Altar 15 (Robichaux, 2010: 126). Aquí, la lectura es mucho más dudosa, ya que el monumento está muy erosionado y su contexto es aún más difícil de comprender, aunque acompaña lo que parece ser el título de kalo'mte'.

En ambos casos, es complicado asegurar a qué se debe la presencia del GE del murciélago en estos monumentos, ya que resulta muy difícil ver las características formales del compuesto jeroglífico. En los primeros estudios sobre Oxpemul, se indica que su GE es un trono de piedra (Grube, 2005: 96; Robichaux y Pruett, 2005), por lo que cabría la posibilidad de que el GE del murciélago haga referencia a visitantes extranjeros, aunque Grube argumenta que es más bien el GE del murciélago el que representa a los habitantes de Oxpemul en etapas tardías de su historia (Grube, 2008: 199), y no el trono que él mismo había propuesto con anterioridad, aunque éste aparezca asociado al topónimo de Ux Te' Tuun, nombre vinculado a su vecino Calakmul. En esta misma publicación reporta la presencia de 
otro ejemplo del GE del murciélago, presentado a la par que el del trono de piedra, en la Estela 7 de Oxpemul.

Además de Oxpemul, y según la propuesta de Simon Martin (2005), el GE del murciélago aparece también en tres inscripciones de Calakmul. El primer ejemplo de la presencia de este GE se encuentra en la Estela 114, fechada para el 431 d.C., en la que, de acuerdo con Martin (2005), aparece un GE con la cabeza de un murciélago. Esta versión del quiróptero es muy temprana y no parece poseer las características del GE de Copán. Martin sugiere que se trata de un gobernante local, ya que en la inscripción se indica que el individuo es un señor de Chi'k Naahb', topónimo asociado con Calakmul.

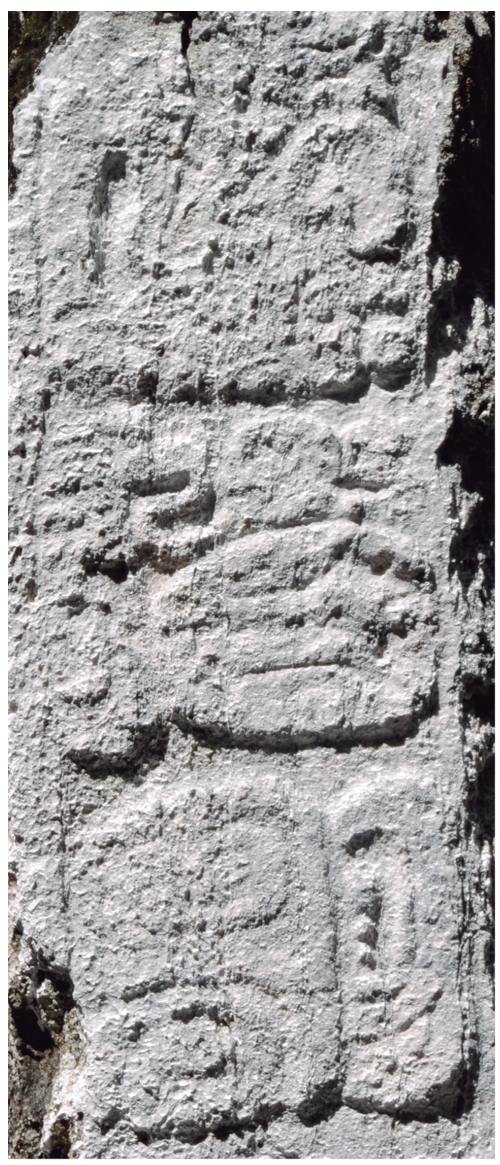

a

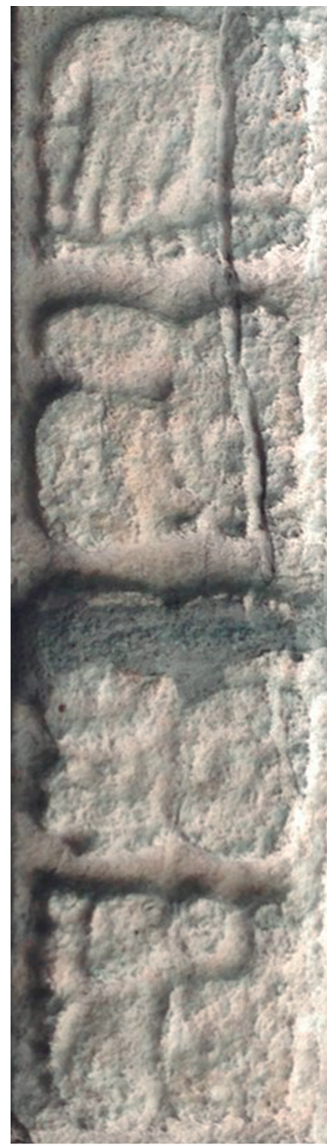

$\mathrm{b}$

Figura 3. Ejemplos del GE del murciélago en Calakmul: a) Estela 59, b) Estela 62. Fotografías de Rogelio Valencia, con la autorización del Proyecto Arqueológico de Calakmul. 
Posteriormente, Martin menciona la Estela 59, fechada en 741 d.C., en la que el primer cartucho legible, en la parte superior del texto, se asemeja a la figura de un murciélago (Figura 3a). Después de una inspección detallada del monumento, podemos asegurar que se trata de un Glifo Emblema y que el único animal que tiene una oreja como la que claramente se puede ver en la Figura 3a, y que además forma parte de un GE, es el murciélago. Asimismo, parece poseer los elementos circulares que se asemejan a los elementos iconográficos de la piedra que aparecen asociados al GE de Copán (Martin, 2005: 7), pero por su estado resulta muy difícil poder asegurarlo. La inscripción parece estar datada para el 9.15.10.0.0, 30 de junio de 741 d.C. (Martin, 1998), fecha asociada a otro conjunto de estelas localizadas frente a la Estructura VI. En su lado derecho, además de mostrar la fecha, parece incluir el sustantivo relacional, ukabaaj, ${ }^{2}$ 'con la supervisión de', antes del nombre del personaje asociado con el GE del murciélago, que indica la supervisión de dicha persona sobre la acción indicada por el verbo, la cual resulta muy difícil de leer. El texto del lado izquierdo incluye claramente una clausula verbal, CHUM-mu-ja, chuhmaj, ${ }^{3}$ 'él se sentó' (tercer grupo de signos en la Figura 3a), indicando la acción de ascender al trono y también una referencia a un apelativo (9-CHAN/CHAK?) que aparece relacionado con el gobernante Bolon K'awiil en la Estela 58, localizada en el costado este de la Estructura XIII. En la Estela 59, dicho apelativo aparece precedido por la palabra AJAW-wa, ajaw, 'gobernante'. Resulta claro que el GE del murciélago en tal caso no hace referencia a un gobernante de Calakmul, pues éste es mencionado en una clausula diferente. Para estos momentos, la historia de Copán es bastante convulsa, pues solo tres años antes, en el 738 d.C., Waxaklaju'n Ubaah K'awiil fue decapitado por su rival de Quiriguá, K’ahk' Tihliw Chan Yopaat (Martin y Grube, 2008: 205), estando posiblemente involucrado en la conjura de Quiriguá contra Copán el gobernante anterior a Bolon K'awiil, Wamaw K'awiil (Martin y Grube, 2008: 114, 219), quien quizá también tuvo cierto control sobre el reino de Hix Witz (Tunesi, 2007). En resumen, si lo anterior es correcto, la estela parece mencionar un evento desconocido que fue supervisado por un personaje asociado al GE del murciélago $\mathrm{y}$, posteriormente, menciona la entronización de Bolon K'awiil, estando ambos eventos probablemente relacionados.

El último monumento que menciona Martin (2005) es la Estela 62, fechada en 751 d.C. y localizada actualmente en el Museo Nacional de Antropología de la Ciudad de México (Figura 3b). El texto donde aparece el GE del murciélago se

2 La expresión ukabjiiy puede proceder del verbo "hacer" o "gobernar" (chab en tzotzil colonial). En otras palabras, dicha expresión podría interpretarse como un verbo en estatus perfecto o perfectivo, que es una forma transitiva, y traducirse como "él lo ha hecho" o "él lo ha gobernado" (Comunicación personal de revisor anónimo, 2017).

${ }^{3}$ La presencia del posicional chuhmaj, "sentarse", para el 741 d.C. puede deberse a un intento del escriba por mostrar una forma arcaica de dicha expresión verbal, ya que para esas fechas se emplea la expresión chumlaj. Una explicación menos probable sería la presencia de una forma tzeltalana para expresar el verbo en esta región (Lacadena et al., 2010: 50). 
encuentra en la parte inferior derecha de la parte frontal de la estela. Su estado impide la realización de una lectura fiable, pero su contexto de aparición es el correcto, ya que al inicio de la oración se encuentra el verbo "esparcir", por lo que en el texto debe seguir un nombre propio y algún título. Es imposible ver las características del GE de forma que se pueda comparar con el de Copán.

Un factor interesante a tomar en consideración es el hecho de que existen un par de menciones a un personaje con un nombre similar al que aparece en la Estela 62, el cual parecer ser Yax Chit K'ahk' ... Naah Chan, dentro del corpus de Calakmul (Figura 4), y en uno de ellos se indica claramente que es un kaanu'l ajaw, por lo que resulta posible que este personaje utilizara ambos glifos emblema en distintos momentos, o bien para diferentes ocasiones.
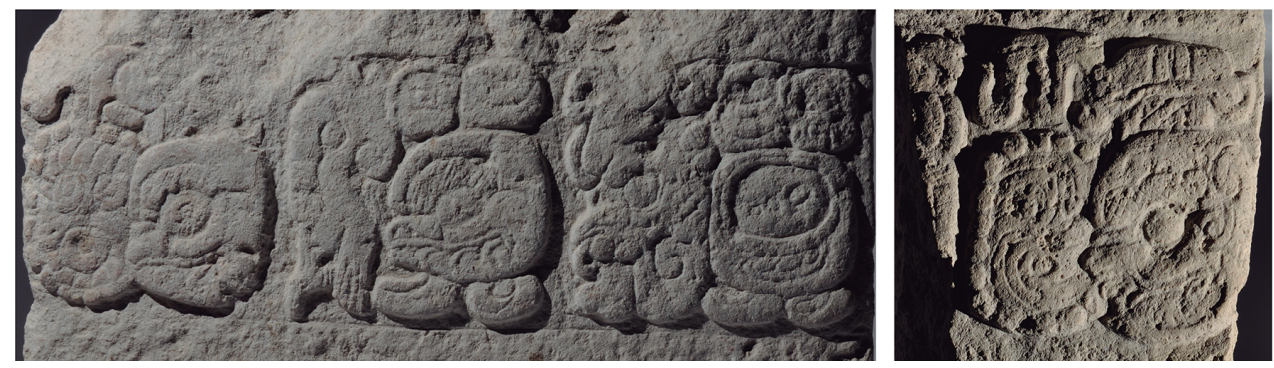

Figura 4. Bloques a) 2273 y b) 504-3, donde aparece un nombre similar al del gobernante de la Estela 62 de Calakmul. Fotografía de Rogelio Valencia, con la autorización del Proyecto Arqueológico de Calakmul.

Además de las menciones anteriores al GE del murciélago, contamos con otro par de sitios en los que la literatura refiere la aparición del mismo. El primero es Uxul, donde sus investigadores (Grube y Paap, 2005; Grube, Delvendahl y Seefeld, 2012: 23) señalan el uso de este GE en la Estela 17, fechada por estilo hacia la primera mitad del Clásico Tardío. En dicho monumento, se habla de un personaje con los títulos Mam Sak Wahyis y, posteriormente, aparece un GE del murciélago que, según Grube, tiene un uso local (Grube y Paap, 2005). El GE está muy erosionado y es imposible ver sus características formales, aunque en el otro cartucho jeroglífico presente en el frente de la estela se puede leer: u-KAB-ji, ukabaaj, 'bajo la supervisión de', lo cual claramente indica que en alguna otra parte del texto debe haber sido incluido el nombre de un gobernante o de algún personaje importante.

También la Estela 3, fechada en el 632 d.C. y pareada con la Estela 2, cuenta con otra mención a este GE, asociado a su vez con un título de kalo'mte' y que, en opinión de Grube (2008: 219), parece ser un GE extranjero, no vinculado con Uxul, que bien podía estar asociado al gobernante mostrado en la Estela. Este es un ejemplo extraño, pues el GE va antecedido por el compuesto jeroglífico de kalo'mte', siendo que lo común en esta región es escribir primero el GE y posteriormente dicho título. El otro monumento, la Estela 2, muestra a una mujer que aparece vinculada a los títulos K'uhul Chatahn Winik y Sak Wahyis. 
El otro sitio citado por Grube (2005: 100) es Balakbal, donde en la Estela 5 aparece nuevamente el GE del murciélago. Resulta interesante notar que, en una publicación más reciente (Grube, 2008: 183), el mismo autor no hace mención a ese GE del murciélago para dicha estela.

Por último, y de manera muy importante, tenemos la utilización del GE del murciélago en Naachtún, en la Estela 23. Grube fue el primero en identificar la presencia de este GE en tal lugar (Grube, 2005: 99), indicando que se trataba de un personaje que realiza una visita al sitio y no de un gobernante local. Pero en recientes investigaciones llevadas a cabo por parte de los investigadores del Proyecto Arqueológico Petén Norte-Naachtún, bajo la dirección de Philippe Nondédéo, los epigrafistas Alfonso Lacadena e Ignacio Cases han podido determinar con toda certeza que el GE del sitio es el de la cabeza de murciélago (Cases y Lacadena, 2015). La Estela 23 habla de un gobernante local con este título en la fecha 8.16.4.10.1 (361 d.C.), que antecede a la que aparece en la Estela 114 de Calakmul. Asimismo, mencionan la aparición de otro gobernante con el mismo GE en la Estela 24, fechada para 8.17.1.4.12 (378 d.C.). Ambos gobernantes son locales, por lo que se puede asegurar que, por lo menos durante el Clásico Temprano, los gobernantes de Naachtún utilizaban al murciélago como GE de manera simultánea a los señores de Calakmul y a los señores de Copán.

Tomando en consideración los ejemplos mencionados hasta el momento, la evidencia de que el GE del murciélago utilizado en Copán haya sido empleado en esta región del Petén es muy endeble, siendo la única posible excepción la Estela 59 de Calakmul. Son muy pocos los ejemplos documentados, su contexto es muy dudoso y el estado de conservación de las inscripciones impide una lectura fidedigna que permita identificar las características específicas del GE de Copán.

Por otra parte, la evidencia presentada por el proyecto Naachtún apunta a la existencia de dos entidades políticas diferentes que empleaban un GE muy parecido, una con clara presencia en el extremo oriental de la zona maya y la otra muy activa en el sur del Petén. Esta última, la de Naachtún, alcanzó cierta influencia durante el Clásico Temprano en sitios que le eran próximos, tales como Uxul, Balakbal y, posiblemente, Calakmul, con un probable resurgimiento hacia el Clásico Tardío, tal y como lo señalan los ejemplos de Oxpemul y la Estela 62 de Calakmul. Esto indicaría que se mantuvo viva en la región de Calakmul, esperando una oportunidad para volver a ser preponderante en esta región, pero nuevas evidencias parecen indicar que la de Copán también jugó un papel interesante en la historia de Calakmul.

\section{La evidencia de El Palmar}

El hallazgo de la Escalera Jeroglífica del Grupo Guzmán de El Palmar (Figura 5) ha cambiado de alguna forma nuestra comprensión del empleo del GE del murciélago en la región central del Petén debido a que, por primera vez y de forma fidedigna, 
se identificó sin ambigüedades, encontrándose relacionado con uno de los jerarcas más prominentes de Copán, así como con las deidades protectoras de dicho asentamiento (Tsukamoto, 2014; Tsukamoto y Esparza, 2015).

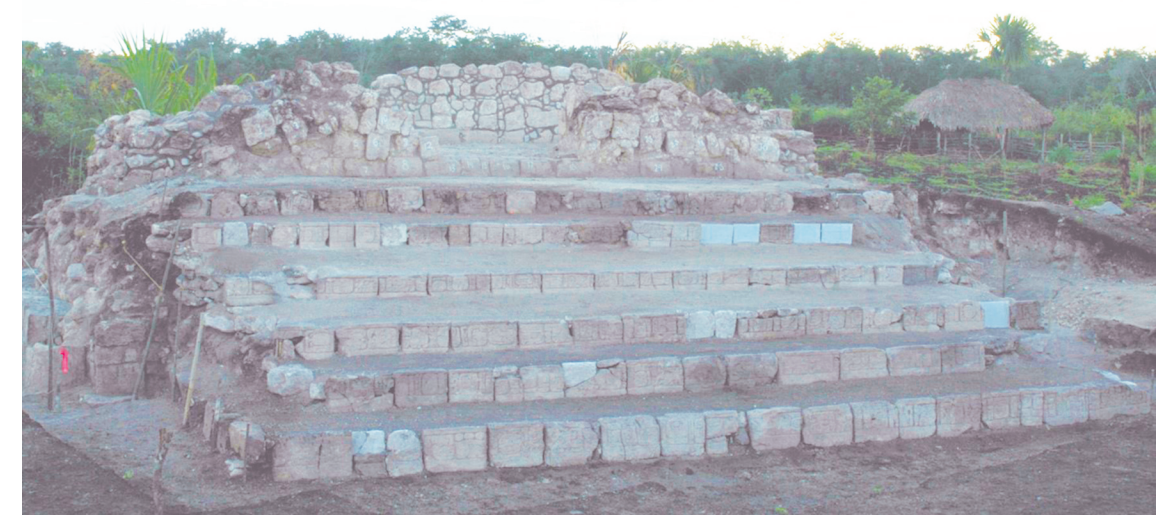

Figura 5. Escalera Jeroglífica 1 de El Palmar. Fotografía de Kenichiro Tsukamoto.

La primera mención del GE del murciélago dentro del texto de la escalinata se ubica en el primer peldaño (Figura 6a), donde se encuentra asociado con la ciudad de Copán y su decimotercer gobernante, Waxaklaju'n Ub'aah K’awiil. La fecha relacionada con esta referencia puede reconstruirse en el sistema de Cuenta Larga como 9.14.14.13.19 (24 de junio de 726 d.C.) y narra la travesía de un individuo de El Palmar (casi con seguridad de Ajpach' Waal, quien aparece como un personaje central dentro del texto) a Copán para efectuar una especie de comparecencia ante el señor de esta ciudad y las deidades patronas de la misma.

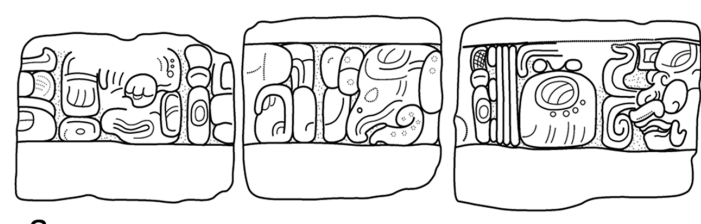

a

b
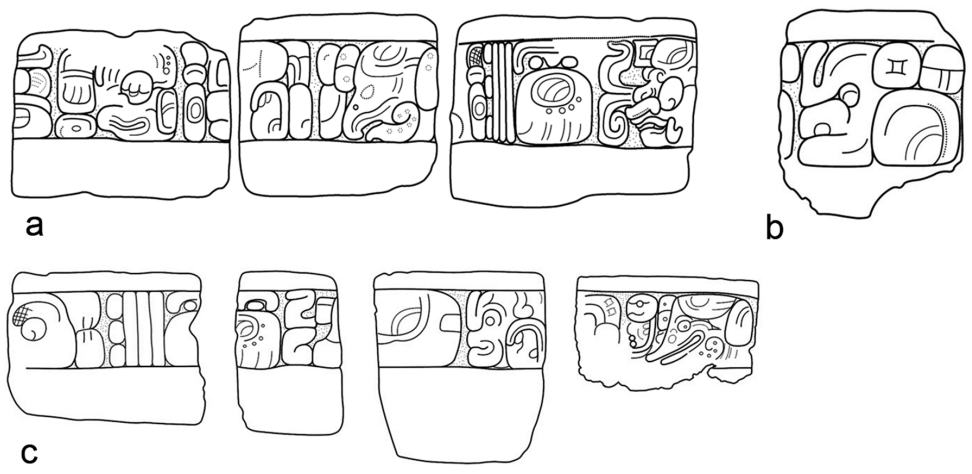

Figura 6. a) Peldaño 1 de la Escalera Jeroglífica 1 de El Palmar, b) segundo ejemplo en el peldaño 5 de la Escalera Jeroglífica 1 de El Palmar, $c$ ) primer ejemplo en el peldaño 5 de la Escalera Jeroglífica 1 de El Palmar. Dibujos de Octavio Esparza. 
La segunda referencia está contenida en el quinto peldaño (Figura 6b), donde el GE del murciélago está nuevamente ligado al nombre de Waxaklaju'n Ub'aah K'awiil. En esta ocasión, el gobernante de Copán parece ser testigo de algún evento vinculado con la escalinata jeroglífica en la fecha 9.14.15.0.0 (13 de septiembre de 726 d.C.), apareciendo a la par de otros insignes personajes como Yuhkno'm Tok' K'awiil, señor de Calakmul, y un gobernante de El Palmar cuyo nombre se encuentra severamente erosionado en la inscripción. En ambos casos podemos ver la presencia de los elementos iconográficos de piedra, pero separados del logograma del murciélago, es decir, como un logograma TUN o la sílaba -ku, y en el primer caso aparece también el sufijo -pi.

La mención de Waxaklaju'n Ub'aah K'awiil junto a la de Yuhkno'm Tok' K'awiil resulta sorprendente, debido a la escasez de referencias que existen de Copán en inscripciones de la zona del Petén. Lo mismo sucede respecto a los ejemplos conocidos del GE de la serpiente en monumentos de la región del Río Motagua, donde sólo contamos con el texto de la Estela A de Copán, con una enigmática referencia a un señor de Chi'k Naahb' en la Estela I de Quiriguá y con la posible mención en la Estela 59 de Calakmul sobre la cual ya hemos hablado en el apartado anterior. La inscripción de la Estela I de Quiriguá es relevante, debido a que parece indicar la injerencia de un personaje de Calakmul, de nombre Wamaaw K'awiil, en el conflicto que mantuvieron Copán y Quiriguá en 738 d.C. (Martin y Grube, 2008: 114, 219).

En ese momento parece que los gobernantes de Chi'k Naahb' mantuvieron una especie de alianza con K'ahk' Tihliw Chan Yopaat (gobernante de Quiriguá) para lograr derrotar a Copán, acción que contrasta con el posible encuentro del año 726 d.C. entre Waxaklaju'n Ub'aah K'awiil y Yuhkno'm Tok' K'awiil, así como con la probable mención de un gobernante de Copán en la Estela 59 de Calakmul. $\mathrm{Si}$ bien es cierto que el texto de la Escalera Jeroglífica de El Palmar no es claro en torno al tipo de relaciones que mantuvieron Calakmul y Copán, éstas parecen haber sido cordiales, al permitir Calakmul la interacción entre uno de sus sitios satélite y la distante urbe copaneca.

Sin duda, el vínculo entre las esferas políticas de Copán y Calakmul plasmado en la Escalera Jeroglífica de El Palmar abre nuevas posibilidades respecto a la interpretación del corpus de inscripciones de Calakmul, tales como la Estela 59 de este sitio, para la cual Simon Martin ya había vislumbrado un probable nexo entre Copán y lo que él interpretó como la cabeza de un quiróptero en dicha estela:

Las aparentes marcas ‘de piedra' que aparecen en la mejilla del murciélago inicialmente me hicieron pensar en el glifo emblema de Copán, especialmente considerando la proximidad temporal de la guerra entre Quiriguá y Copán en la que Calakmul pudo tener alguna injerencia, aún tenue y que ocurrió en el año 738. No es posible descartar la existencia de alguna relación entre estos dos glifos emblema con sendas cabezas de murciélago, pero es importante hacer notar que las versiones halladas en Calakmul carecen del componente pi y/o pu hallados en Copán (Martin, 2005: 7). 
Esta aseveración de Martin también se relaciona con la tercera mención del GE del murciélago que aparece en el quinto peldaño de la escalinata. Aunque el bloque que contiene dicha mención fue encontrado fuera de contexto, su ubicación original más probable es en la parte final de la hilera, debido a sus características físicas y a las dimensiones de los bloques faltantes en la última parte de la quinta grada. En este caso (Figura 6c), dentro de los componentes de la cabeza del murciélago se aprecia el logograma TUN, 'piedra', pero carece del silabograma pi tal y como sucede en los ejemplos de Calakmul. Aunque tomando en cuenta las referencias existentes al GE de Copán en otros pasajes de la escalinata y a la relevancia que se le da a Waxaklaju'n Ub'aah K'awiil y a las deidades protectoras de su ciudad, es probable que se trate de una tercera referencia al GE de Copán, aunque en este caso se haya elidido la representación del silabograma pi, típico en las inscripciones jeroglíficas de Ux Wintik que, como se indicó en la introducción, en ocasiones no aparece y que concuerda con el ejemplo encontrado en la Estructura I de Chi'k Naahb' en Calakmul, del cual hemos hablado antes (vid supra).

La aparición del texto de la Escalera Jeroglífica de El Palmar cambia un poco la situación hasta ahora descrita dado que, en realidad, sí existe una referencia clara en el Petén Central a un señor de Copán, es decir, a un señor asociado con el GE del murciélago. Asimismo, la inscripción de El Palmar no solamente nos habla de Waxaklaju'n Ub'aah K'awiil, sino que menciona también a un señor de Calakmul, indicando que existe un vínculo entre ambos reinos. Si bien resulta interesante que la mayor parte del texto no tiene como protagonistas a señores de El Palmar, sino a un grupo de lakam que habitaba en un pequeño sector ubicado en el extremo norte del asentamiento.

Ante este escenario, el vínculo con la urbe copaneca podría corresponder a un tema administrativo pues, de acuerdo con Lacadena (2008), el cargo de lakam lo ostentaban personajes asociados con el tributo y la leva de hombres para la guerra. Por otra parte, también debemos considerar la opinión de David Stuart respecto a que los lakam bien pudieron actuar como una especie de embajadores (Stuart, 1992; Tsukamoto, 2014). Bajo esta última interpretación podemos pensar en el grupo lakam de El Palmar como emisarios que visitaban las cortes reales de otros centros mayas.

Sin embargo, no hay una sola inscripción en Copán que indique que las relaciones entre los reinos del murciélago y la serpiente fueran estrechas, aunque existen menciones como la de la Estela $\mathrm{A}$, de carácter muy genérico, realizada precisamente por Waxaklaju'n Ub'aah K'awiil, donde el GE de Copán aparece junto a los de las dinastías de Kaanu'l, Baaku'l y Mutu'l.

De esta forma, la Escalera Jeroglífica del Grupo Guzmán de El Palmar es, hasta el momento, la única inscripción que prueba la relación entre ambos reinos con cierta seguridad, ya que el resto de los textos jeroglíficos provenientes de Copán y Calakmul son poco claros al respecto, aunque hablen de una dinastía del murciélago. 


\section{El poder compartido en Calakmul}

Una de las partes más enigmáticas de la historia de Calakmul se encuentra en su época más temprana, para la que no existen referencias a los señores de Kaanu'l. Parece ser, por lo que se ha visto hasta este punto, que los protagonistas de dicha porción de la historia del sitio fueron los miembros de la dinastía asociada con el GE del murciélago. Si bien esto es verdad, los personajes asociados con tal GE no serían los únicos que pudieron haber ejercido el poder en Calakmul, ya que un poco más tarde del momento en el que se erige la Estela 114 existen menciones jeroglíficas a un grupo de personajes que se autodesignan señores de Ux Te' Tuuny de Chi'k Naahb' (por lo menos en un caso), que son los K'uhul Chatahn Winik. ${ }^{4}$ Este grupo tiene una presencia muy temprana en el sitio de Calakmul y suele aparecer como el creador de las vasijas estilo códice halladas en el sitio (Salinas y Valencia, 2013).

La procedencia de estas vasijas se ha situado históricamente en Nakbé, debido a la evidencia vinculada con el lugar de origen de las arcillas utilizadas para su fabricación y por algunos ejemplos allí encontrados (Hansen, Bishop y Fahsen, 1991), pero Calakmul es el sitio con más ejemplos hallados arqueológicamente y muchos de ellos proceden de talleres locales, pues emplean pastas de origen local, diferentes a las de Nakbé (Boucher, 2014; Boucher y Palomo, 2012; ReentsBudet et al., 2010; Salinas y Valencia, 2013).

El primer indicio de la presencia de los Chatahn Winik en Calakmul aparece en la Estela 43 (Figura 7), fechada para el año 541d.C. Este monumento, localizado al pie de la Estructura II, se halló dentro de un cuarto con la intención de preservarlo (Pincemin et al., 1998), ya sea porque originalmente estaba ahí, o bien porque fue trasladado de otro sitio para construir un recinto a su alrededor (Pincemin et al., 1998: 312; Valencia et al., 2014). El cuarto se encontraba abierto y permitía a la gente circular frente a la estela. Aunque el texto de este monumento resulta críptico, en él se indica claramente que el personaje principal, que posee el título Mam K'uhul Chatahn Winik, pone de pie lo que, probablemente, sea el propio monolito que contiene la inscripción, incluyendo un ejemplo muy temprano del término lakamtuun, "estela".

Si este personaje es el mismo que se encuentra representado en la parte frontal de la estela (Figura 8), no hay duda de que es un gobernante (García Barrios y Velásquez García, 2016: 81; Valencia y Esparza, 2014), pues aparece ricamente ataviado y sosteniendo una barra ceremonial de la que surgen dos deidades, una de ellas corresponde a un bebé K'awiil —uno de los ejemplos más tempranos que se conocen de esta deidad-y la otra al dios solar K'ihnich Ajaw, además podemos ver un par de cautivos a sus pies.

\footnotetext{
${ }^{4}$ Para un estudio detallado del grupo de los Chatahn Winik recomendamos la lectura de los trabajos de Boot (2005: 505-512), García Barrios y Velásquez García (2010, 2016).
} 


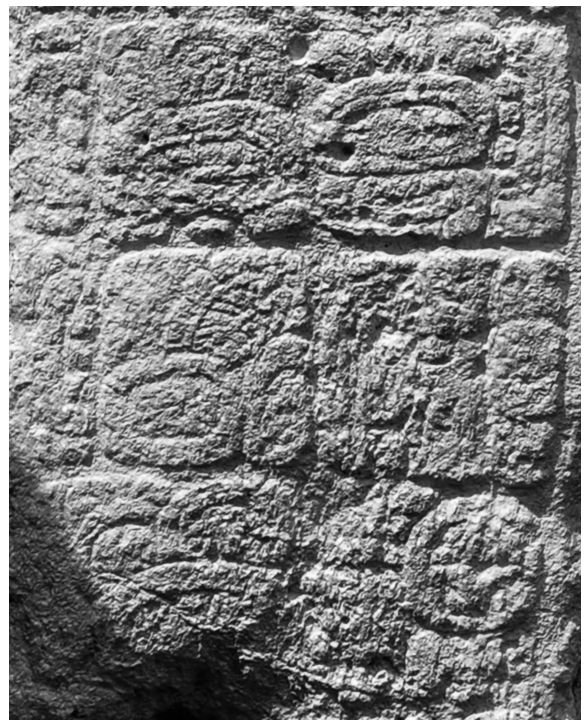

Figura 7. Texto en el que se menciona a un K'uhul Chatahn Winik en la Estela 43 de Calakmul, transcrito como u winikhaab' tz'ahpaj ulakam? tuun Mam K'uhul Chatahn Winik. Fotografía de Rogelio Valencia, con la autorización del Proyecto Arqueológico de Calakmul.

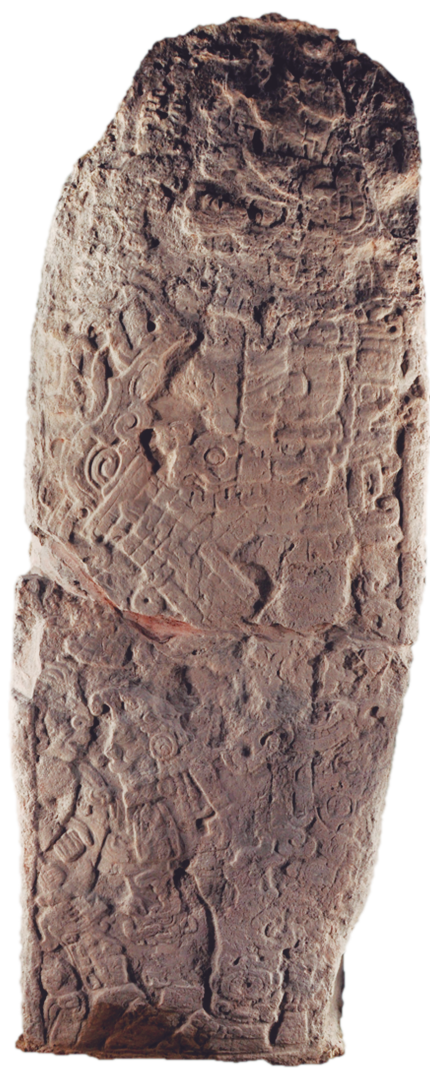

Figura 8. Frente de la Estela 43 de Calakmul, donde aparece un personaje ataviado como ajaw. Fotografía de Rogelio Valencia, con la autorización del Proyecto Arqueológico de Calakmul. 
Otro señor de Chatahn Winik aparece mencionado en la Subestructura Sub XX b-1 (Figura 9), en una banqueta pintada de color rojo y con una inscripción jeroglífica en negro. Aunque esta inscripción carece de fecha, tanto el contexto arqueológico como el estilo caligráfico la fechan para el período Clásico Temprano, por lo que se puede establecer una relación temporal entre ambos personajes.

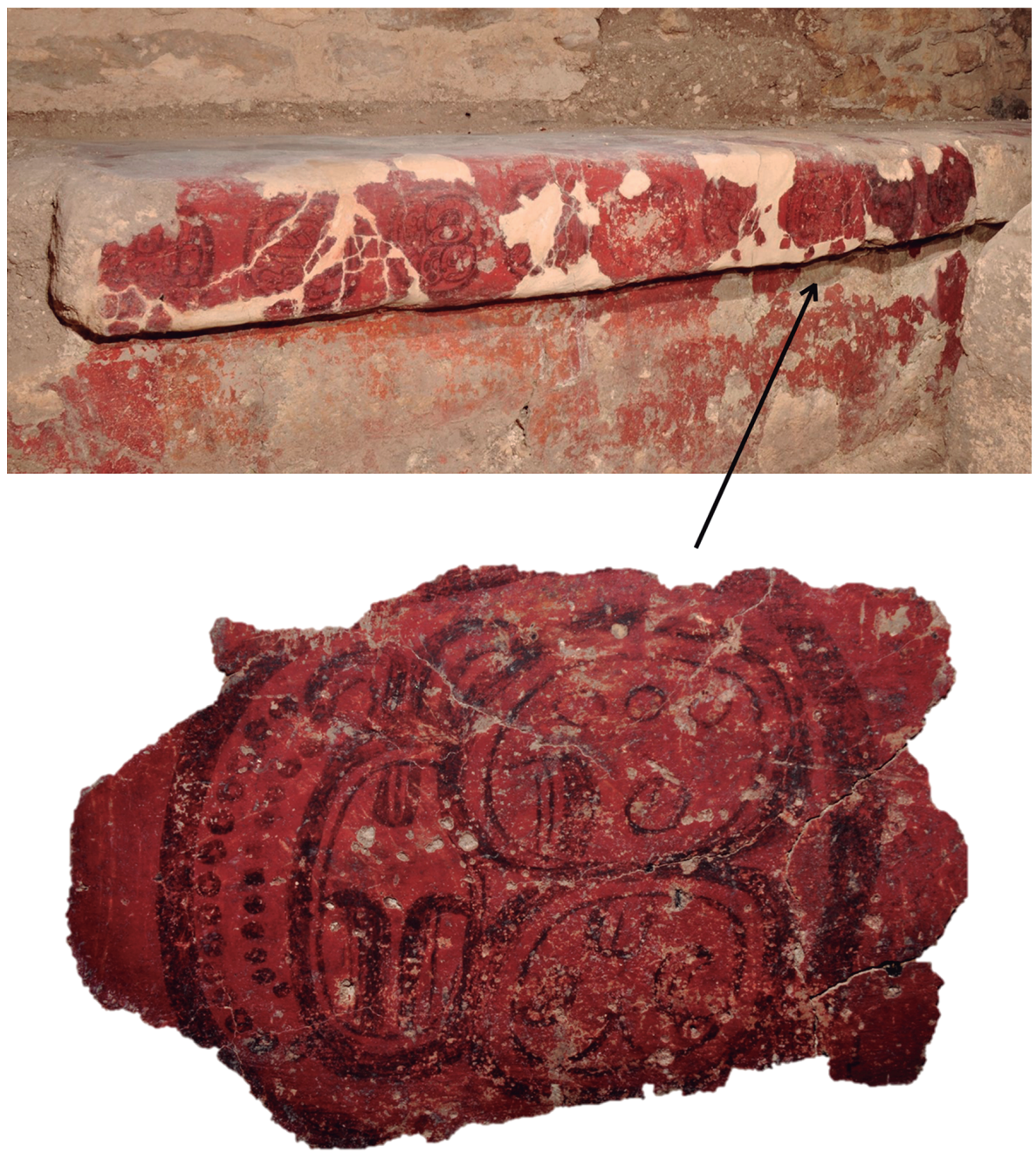

Figura 9. Banqueta de la Subestructura Sub XX b-1, donde se menciona a un K'uhul Chatahn Winik. Fotografía de Rogelio Valencia, con la autorización del Proyecto Arqueológico de Calakmul. 
En dicha inscripción se indica que la banqueta de piedra es la posesión de un tal Mam ... K'uhul Chatahn Winik u Tz'eh K'ab. Resulta interesante que la banqueta vuelva a emplear el término mam, el cual también se incluye en la Estela 43 y que Lacadena (2016) propone actúa como un término reverencial. Posteriormente, la inscripción parece incluir una expresión relacional, yajaw [te'], que vincularía a este señor con otro cuyo nombre se ha perdido, pero que en la parte final de la inscripción se denomina señor de Ux Te' Tuun y de Chi'k Naahb', topónimos de la ciudad de Calakmul. Además, aparece con el título de kalo'mte', considerado como un título de orden superior al de ajaw. Es decir, que el texto bien podría hablar de dos personajes, pues, de acuerdo con Martin (en prensa), esta inscripción lo sitúa como subordinado del señor de Ux Te' Tuun y de Chi'k Naahb'. Sea cual fuere el caso, el personaje es un señor de Chatahn, la banqueta le pertenecía a él, y dicha banqueta se localiza en Calakmul, dentro de una zona residencial asociada con las élites gobernantes, la Gran Acrópolis, en la Estructura XX.

Como bien han indicado varios investigadores (Martin, en prensa; Boot, 2005: Apéndice B y Mathews et al., 2005), el título de Chatahn Winik, o más bien el GE de Chatahn Winik, tiene un carácter dinástico, lo que se puede apreciar gracias a su inclusión como uno de los reinos mencionados en el Altar 3 del asentamiento de Altar de los Reyes, donde aparece al mismo nivel que los GE de Calakmul, Tikal y Palenque (Grube, 2008: 179-181; Mathews et al., 2005).

Por otra parte, David Stuart (2013) ha sugerido que en algunas imágenes plasmadas en vasos del estilo códice, específicamente en las vasijas K1552 y K1647 (Figura 10), se encuentran referencias simbólicas vinculadas a Yuhkno'm Yich'aak K'ahk' (gobernante del señorío de la Cabeza de Serpiente entre los años 686 a 697 d.C.) en asociación con la entidad de Chatahn. Aunque en ambos ejemplos el texto jeroglífico que acompaña a la imagen no hace referencia al poseedor de la vasija, el mismo Stuart menciona que podría tratarse de un personaje llamado Yopaat B'ahlam (que en otras piezas del estilo códice aparece relacionado con el título K'uhul Chatahn Winik) quien, presumiblemente, fue un gobernante local de Nakbé durante el Clásico Tardío, pudiendo ser este último asentamiento un aliado subordinado a Calakmul durante esa época.

En este sentido, vale la pena tomar en cuenta los hallazgos de cerámica estilo códice en Calakmul, donde se han encontrado referencias a personajes de Chatahn, las cuales indican que el sitio pudo ser uno de los principales focos de producción de este tipo de cerámica (Boucher, 2014; Boucher y Palomo, 2012; Reents-Budet et al., 2010). Tal es el caso de una vasija encontrada en la Estructura XXI en la temporada 2012, donde se hace referencia a un individuo nombrado K'ahk' Nahb'il K'uhul Chatahn Winik Sak Wahyis ${ }^{5}$ (Figura 11). Resulta interesante mencionar que una parte de esta vasija fue hallada en una unidad 2016).

${ }^{5}$ Otra propuesta de lectura para este nombre es K’ahk' Yahxb'il (García Barrios y Velásquez García, 

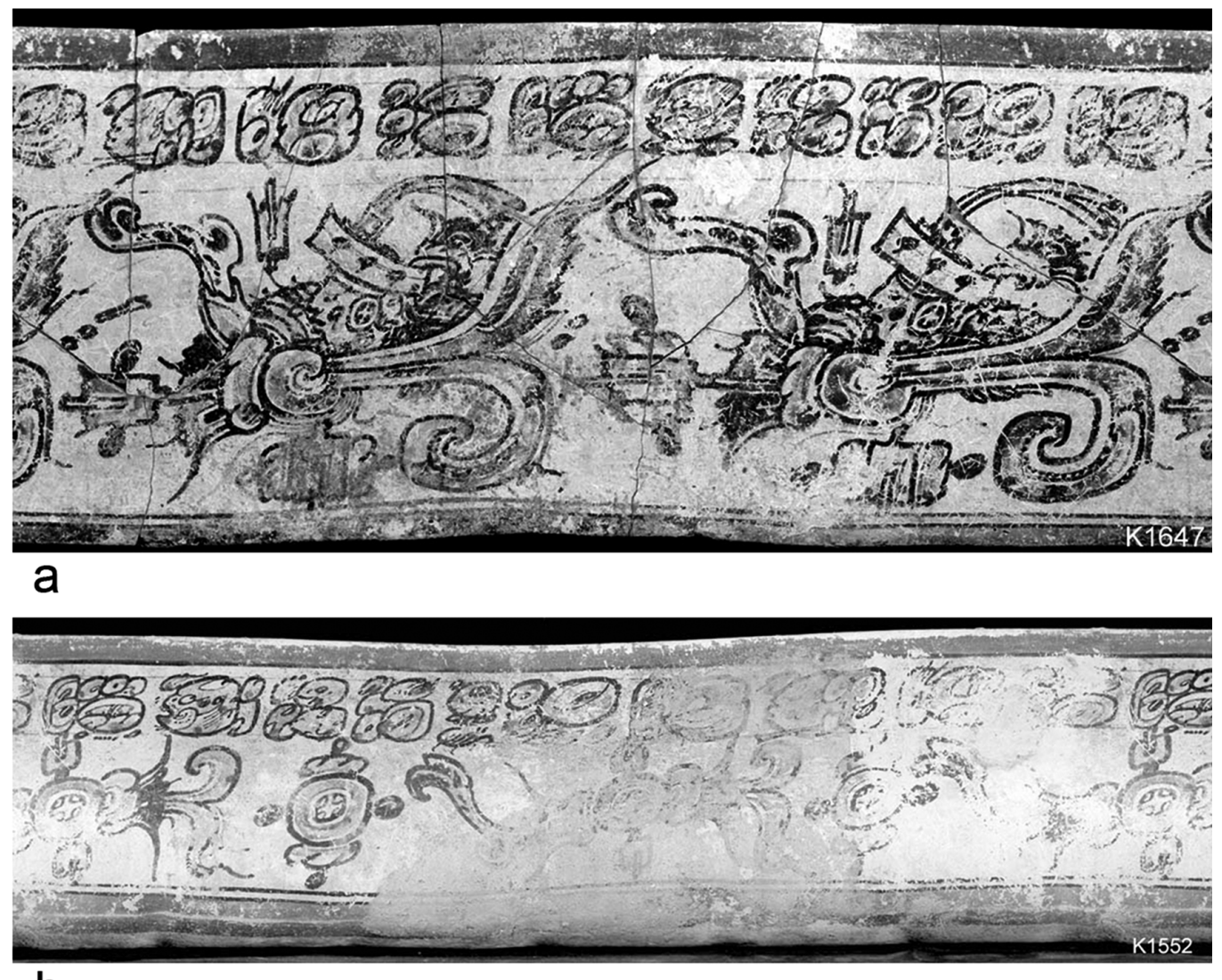

b

Figura 10. Vasijas K1552 y K1647, en las cuales se encuentran referencias simbólicas vinculadas a Yuhkno'm Yich'aak K'ahk'. Fotografías de Justin Kerr.

de excavación de la Estructura XXI (Salinas y Valencia, 2013), mientras que el otro tiesto fue recuperado en un pozo excavado en el pasillo norte localizado entre la Estructura G2 y la Estructura XX, en la Gran Acrópolis, lugar donde también se localizó la banqueta del otro Chatahn Winik que se ha mencionado antes (Boucher, 2014; Carrasco et al., 2005: 47-48). Ambos lugares se encuentran a una distancia aproximada de 30 metros (Figura 12), dando pie a plantearnos si los depósitos donde se localizaron ambas piezas eran basureros, o si en realidad tenían un carácter ritual. Lo interesante es que la Estructura XX parece ser el lugar donde los remanentes de esta dinastía temprana siguieron viviendo dentro de la ciudad, pues es el lugar donde más cerámica de este tipo se ha recuperado y donde se encuentra la banqueta de la cual ya hemos hablado. 


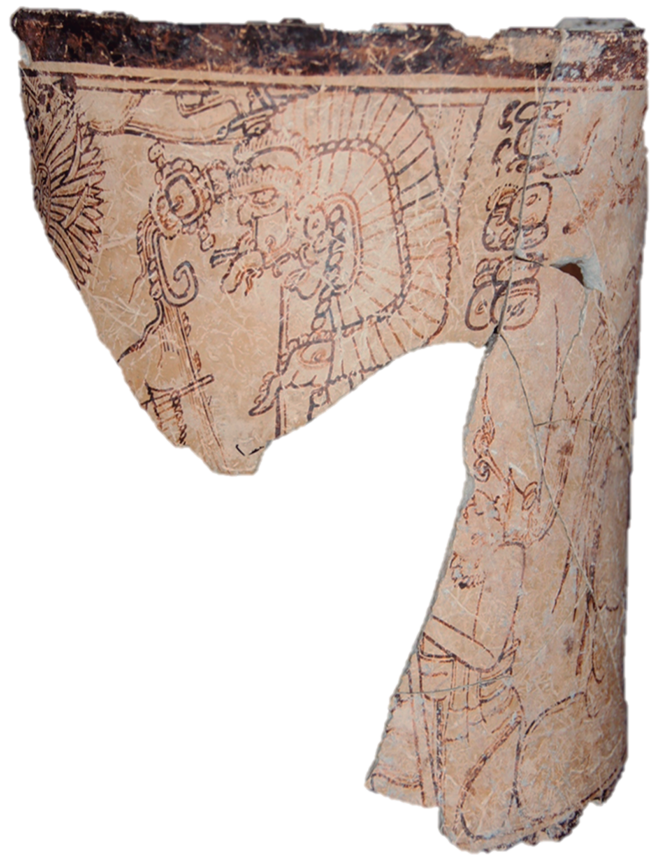

Figura 11. Vasija fragmentada hallada en la Estructura XXI de Calakmul, que se completa con un tiesto encontrado en la Estructura XX del sitio. Transcripción: K'ahk' Nahb'il K'uhul Chatahn Winik Sak Wahyis. Fotografía de Alejandra Salinas.

La asociación entre un gobernante de la dinastía Kaanu'l y la entidad de Chatahn que se exhibe en las vasijas K1552 y K1647, fechadas tentativamente alrededor del año 690 d.C., se suma a otras referencias conocidas del Clásico Tardío como las plasmadas en las Estelas 51 y 89 de Calakmul, donde los artistas que firman la manufactura de las estelas llevan ese GE (Martin, Houston y Zender, 2015) y poseen un nombre que sólo fue empleado por los miembros de la familia gobernante, Yuhkno'm, mostrando así la continuidad de los lazos que mantuvieron distintos personajes de Chatahn con Calakmul desde épocas tempranas, como queda manifestado en la Estela 43 y en la banqueta de la Estructura Sub XX b-1.

En este punto podemos sugerir, con la evidencia disponible, que tanto el linaje de Chatahn como el del murciélago bien pudieron coexistir dentro del mismo Calakmul desde el Clásico Temprano hasta el Tardío, siendo posteriormente asimilados por los señores de Kaanu'l, con quienes acabarían compartiendo lazos familiares. Posiblemente, las dinastías de Chatahn y el Murciélago asumieron un rol secundario debido a la preponderancia de una de las dinastías más pujantes del Clásico maya, esperando una oportunidad para resurgir, como lo evidencia la presencia del GE del murciélago en la Estela 62. Este tipo de composición sociopolítica ya ha sido sugerida empleando otro tipo de evidencia arqueológica, 


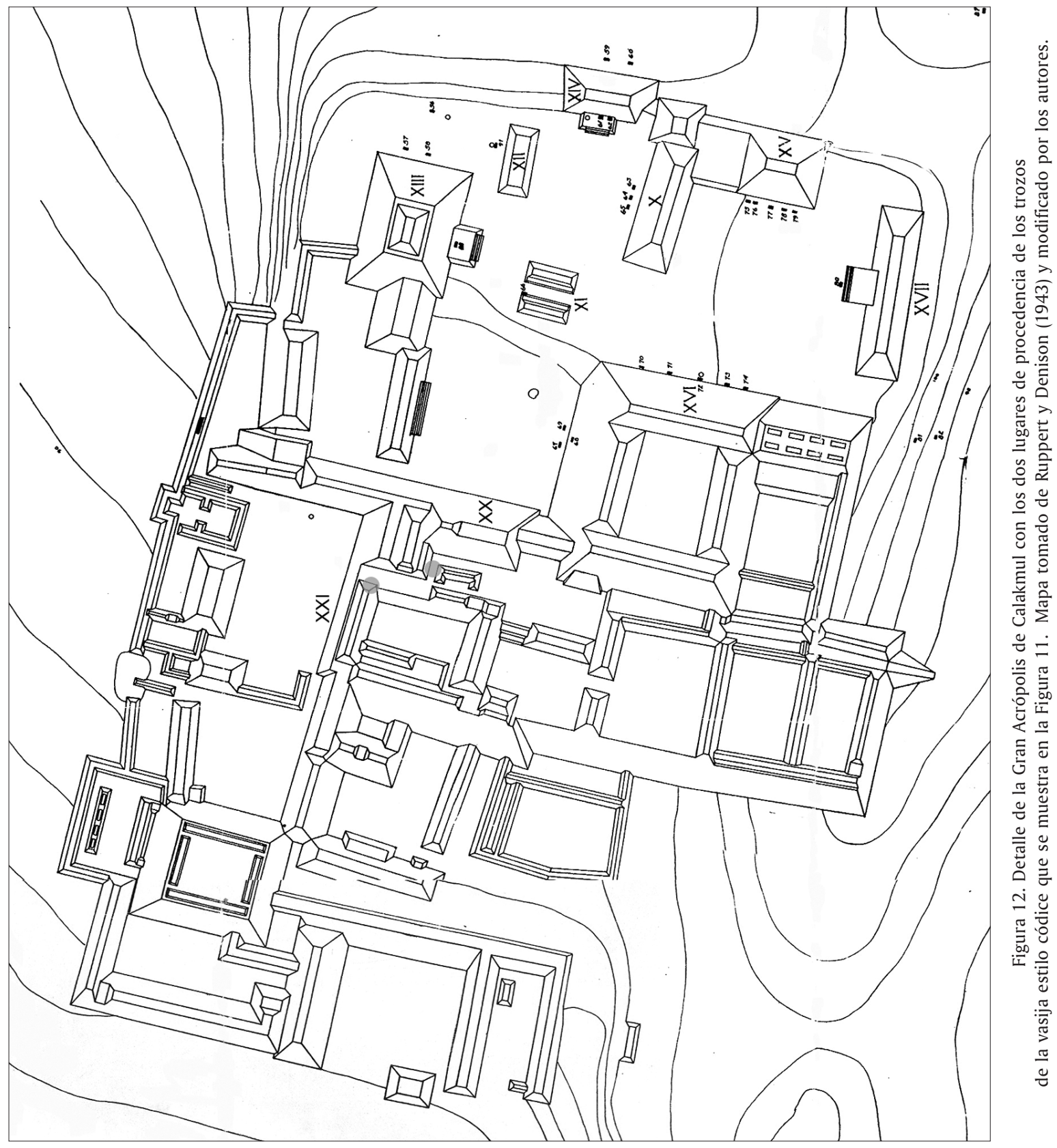


como la relativa a la conformación de las plazas públicas de las ciudades mayas (Bazy, Valdés y Arnauld, 2010; Valencia, Carrasco y Cordeiro, en prensa) mediante el estudio de la conformación de las plazas en diferentes sitios a lo largo de su historia, pues refieren a cambios que las llevan de ser públicas a privadas y viceversa, apuntando a la prominencia de los grupos que las empleaban en determinados momentos de su historia, lo cual se demostraba mediante la transformación de rituales privados en rituales públicos, indicando una lucha constante entre diversas facciones o grupos de poder (Bazy, Valdés y Arnauld, 2010: 196-197).

Esta circunstancia particular en Calakmul resulta ser de sumo interés, debido a que en épocas recientes se había establecido que la entidad política de la Cabeza de Serpiente tuvo su asiento en Dzibanché durante el Clásico Temprano para, posteriormente, emigrar hacia Calakmul en algún momento del siglo VII d.C. Sin embargo, resulta plausible la hipótesis que plantea la existencia de dos grupos que clamaban el mismo linaje y que, en opinión de Erik Velásquez García (en prensa), bien pudieron coexistir durante un lapso del Clásico Temprano: uno de filiación linguística cholana oriental, establecido en Dzibanché, y otro, de filiación cholana occidental, asentado en Calakmul. En este aspecto cobra gran relevancia el texto hallado recientemente en Xunantunich (Helmke y Awe, 2016a y 2016b) donde se indica que para el 642 d.C. no hay gobierno en la ciudad de los Kaanu'l, pero sí en Ux Te' Tuun, lugar asociado con la actual ciudad de Calakmul (Martin y Velásquez García, 2016).

Por otra parte, el uso de un mismo glifo emblema por diferentes grupos no es algo desconocido en el área maya; ejemplos de una situación similar pueden observarse en los sitios de Palenque y Tortuguero, El Zotz y Yaxchilán o Tikal y Dos Pilas.

\section{La refundación de la dinastía}

Dentro de esta discusión, un dato interesante es el que procede del texto de la escalinata jeroglífica hallada recientemente en la Estructura 13R-10 de La Corona (Barrientos, Canuto y Ponce, 2012: 156). En el Bloque V de dicha escalinata se hace referencia al establecimiento ${ }^{6}$ de la corte Kaanu'l en el sitio de Calakmul, que tuvo lugar en la fecha de Cuenta Larga 9.10.2.4.4 12 k'an 17 uo (8 de abril de 635 d.C.), poco tiempo antes del acceso al poder de Yuhkno'm Ch'e'n II, gobernante que afianzó el dominio de la dinastía Kaanu'l y estableció una intrincada

\footnotetext{
${ }^{6}$ Esta acción se menciona en dicho panel mediante un logograma que no se ha decifrado aún, representado por un signo de haab incrustado dentro del silabograma -yi. Como indican Helmke y Awe (2016b: 18) el logograma posiblemente termine en $-y$, pero esto no tiene por qué ser necesariamente así, ya que el signo puede formar un logograma compuesto por ambos elementos, tal y como parece sugerir el hecho de que un signo esté superpuesto al otro. Existen dos propuestas de lectura para este signo, la primera, por Beliaev (2013: 112-113), sería kaj, "establecerse”, y otra más elaborada por Sheseña (2015: 97-110), como k'otoy, que en ch'orti significa "llegar".
} 
red de aliados subordinados en varios puntos del área maya (Stuart, 2012; Stuart y Baron, 2012: 196-198). Igualmente, dicho jerarca fue una figura prominente que sirvió como referencia de una cuenta dinástica corta adoptada por los soberanos Kaanu'l de Calakmul en sus registros escritos (Martin, 2005: 8).

Es sabido que en otras cortes mayas los procesos de fundación o, en todo caso de refundación, estaban vinculados a cambios trascendentales, relacionados de forma íntima con el establecimiento de las cortes reales en localidades específicas. Un ejemplo de esto puede observarse en el sitio de Machaquilá, donde tanto el registro arqueológico como el epigráfico apuntan a la existencia de este reino desde épocas muy tempranas, alrededor del Preclásico Tardío o el Clásico Temprano, y a su fundación durante algún momento del Clásico Tardío en la localidad que actualmente conocemos (Ciudad Ruíz y Lacadena, 2006). En el caso de Calakmul contamos actualmente con suficiente evidencia como para suponer que la dinastía de Kaanu'l se escindió en dos facciones. Estando originalmente localizada (posiblemente) en Dzibanché (Velásquez García, 2008, en prensa; Martin, 2005; Martin y Velásquez García, 2016), acabó ubicándose en Calakmul. La aparición de los Paneles 3 y 4 de Xunantunich (Helmke y Awe 2016a, 2016b) nos han permitido determinar que hubo un conflicto, posiblemente fratricida, entre Waxaklaju'n Ub'aah Chan y Yuhk'no'm Ch'e'n II, que terminó con la relocalización de la dinastía en Calakmul, siendo éste finalmente un caso similar al sufrido por la dinastía de Mutu'l (Houston, 1993; Martin y Grube, 2008: 42-43, 56-58), la de Baaku'l (De la Garza, Bernal y Cuevas, 2012: 80) o la de Sak Nikte' (Baron, 2016: 140-142), donde diferentes facciones de la misma dinastía luchan por su control y terminan dividiéndose o matándose entre ellos, como en el caso de La Corona.

En el caso de la facción de los Kaanu'l que se estableció en Calakmul, es probable que se encontraran con una situación en la que la ciudad hubiera estado dominada por dos linajes diferentes durante el Clásico Temprano, el de Chatahn Winik y el del GE del murciélago, estando este último posiblemente asociado con la corte de Naachtún y no con la de Copán. Estos antiguos linajes tuvieron que adaptarse a una nueva situación política tras la llegada del linaje Kaanu'l hacia el 635 d.C., dentro del cual ya no tenían el papel preponderante (Valencia y Esparza, 2014). Es importante señalar que dicho caso diferiría del que hemos analizado con anterioridad para las dinastías de Kaanu'l, Baaku'l y Sak Nikte', donde una misma dinastía tiene conflictos internos que desembocan ya sea en la escisión del adversario o en su eliminación. En el caso de los Kaanu'l frente a los Chatahn Winik, o los dignatarios con el GE del murciélago, estamos hablando de tres dinastías diferentes que deben resolver el conflicto de compartir una misma ciudad.

Dada la presencia de los glifos emblema de la Estela 43 y de la Banqueta Jeroglífica de la Estructura Sub XX b-1 asociados a los Chatahn Winik, mismos que fueron empleados por ciertos nobles de Calakmul durante el Clásico Tardío, así como el empleo del GE del murciélago por parte del gobernante representado en la Estela 62, podemos pensar que ambas dinastías coexistieron durante un cierto período, para después jugar otro papel político, dejando el dominio del 
lugar a los señores de Kaanu'l, pero sin desaparecer de la escena, tal y como lo demuestran las evidencias tardías de su presencia. Con el fin de poder comprobar esta hipótesis, sería necesario indagar sobre las causas que propiciaron tal cambio de poder en Calakmul y, especialmente, qué es lo que llevó a los señores de Chatahn y del GE del murciélago a ejercer sólo ciertos cargos en la corte, para dejar el dominio de la ciudad en manos de los de Kaanu'l, así como la reaparición tardía del GE del murciélago siendo empleado nuevamente por un gobernante maya de Calakmul.

\section{Conclusiones}

De acuerdo con la evidencia presentada, la única mención incontrovertible al Glifo Emblema del murciélago proveniente de Copán en la región central del Petén es la encontrada en la Escalera Jeroglífica de El Palmar, con la posible excepción de la Estela 59 de Calakmul, debido a que parece contar con los elementos iconográficos de "piedra", característicos del GE de Copán. Si bien el texto de la escalinata es una muestra de la relación entre Calakmul y Copán durante los gobiernos de Waxaklaju'n Ub'aah K'awiil y Yuhkno'm Tok' K'awiil, no implica la presencia de Copán en las inscripciones de Oxpemul, Uxul o Naachtún. Esto podría indicar la existencia de otro grupo que ostentaba como GE la figura de un murciélago también en dicha región, cuyas características gráficas formales difieren en la mayor parte de los ejemplos de las del GE de Copán, pues carecen de los signos iconográficos de "piedra" y/o de los sufijos -pi y/o -pu. Según las evidencias presentadas por los epigrafistas del proyecto arqueológico en Naachtún, todo apunta a que este lugar fue el asiento de dicha dinastía.

Dado que tenemos evidencias tempranas del uso del GE del murciélago y de Chatahn Winik anteriores a la aparición de menciones a los señores de Kaanu'l y que, posteriormente, tenemos ejemplos del uso de ambos GE nuevamente hacia finales del Clásico, podemos asumir que los de Chatahn Winik abandonaron el sitio y cuando la dinastía de Kaanu'l perdió fuerza volvieron, o bien que nunca dejaron la ciudad y sobrevivieron a la sombra de una dinastía más poderosa. Ello nos habla de un pasado donde el poder pudo haber estado compartido por diversos grupos en el mismo lugar.

Será interesante averiguar las causas de este cambio en el balance del poder dentro de la ciudad de Calakmul y, especialmente, qué es lo que lleva a los señores de Chatahn Winik a ejercer sólo ciertos cargos en la corte para dejar el poder en manos de los señores de Kaanu'l (Valencia y Esparza, 2014; Valencia et al., 2014; Vázquez et al., 2015).

Con el fin de tener un punto de comparación con una situación semejante, podríamos tomar el ejemplo nahua procedente del Centro de México. Cuando los mexicas llegan a Tenochtitlan, los tepanecas gobiernan el lugar y deciden emplearlos como mercenarios. Una vez que los mexicas adquieren cierto poder, se 
alían con una facción tepaneca, la de Tlacopan, y usurpan el poder de los señores de Azcapotzalco para crear la Triple Alianza, uniendo a Texcoco a la confabulación (Santamarina,1998: 290). Los reinos vencedores crean una triple alianza equitativa que con el tiempo cambia para favorecer a una de las partes, la de los tenochcas, dejando a los tepanecas finalmente un rol secundario, pero siempre como parte de la alianza (Carrasco, 1996: 43-44). Es decir, aun en asociaciones bien estructuradas de grupos de poder termina por imponerse la ley del más fuerte.

Es así como, en el caso de los Chatahn Winik y del GE del murciélago, el cambio de poder puede que no haya sido por la fuerza, sino negociado, ya que ellos subsisten hasta tiempos muy tardíos dentro de la ciudad. Si el grupo de los Chatahn Winik poseía cierta hegemonía sobre una región, tal y como parece indicar su comunión con otro GE, el de Sak Wahyis, el cual también se hallaba complementado por el epíteto de k'uhul como se puede apreciar en inscripciones provenientes de La Corona (Stuart y Baron, 2012: 192), ello implicaría que los territorios asociados a estos dos GE pasarían a estar bajo el control de los señores Kaanu'l. De ser así, esto podría explicar los casos de GE dobles, como los que podemos apreciar en Yaxchilán, donde posiblemente dos grupos unifican sus fuerzas para gobernar la ciudad.

Es muy probable que la coexistencia pacífica de varias dinastías de nobles en un sitio se dé también debido a que éstas estaban emparentadas. Si bien es verdad que en la mayoría de las inscripciones mayas se prima el parentesco patrilineal, la afirmación de orígenes diferentes a la línea principal de ascendencia podría haber sido una vía para asociarse con el resto de los grupos en la ciudad que poseían un cierto peso político, patrocinando una convivencia tranquila entre ellos, de la misma forma que los gobernantes mexicas enviaban a familiares suyos a los sitios recién conquistados, con el fin de establecer nexos familiares con las dinastías locales (Carrasco, 1996).

Por último, es necesario mencionar que todavía necesitamos encontrar varias piezas del complejo rompecabezas que conforma el intrincado conjunto de procesos históricos que atravesó el linaje de la serpiente a lo largo de su existencia, tanto fuera de Calakmul, como al interior del asentamiento. Sin duda, futuros hallazgos nos permitirán desechar o afianzar algunas hipótesis, así como plantear nuevas vías de investigación que aborden enfoques o ideas novedosas en torno a la problemática de la entidad política de Kaanu'l y su relación con la dinastía de Chatahn y el GE del murciélago.

\section{Agradecimientos}

El presente artículo fue originalmente presentado en el simposio "El Glifo Emblema: orígenes y dinámica sociopolítica del título k’uhul ajaw”, del IX Congreso Internacional de Mayistas, organizado por Centro de Estudios Mayas de la Universidad Nacional Autónoma de México, y que tuvo lugar del 23 al 29 de junio de 2013 
en la ciudad de Campeche. Agradecemos a los organizadores de dicho evento y en particular a Verónica A. Vázquez López, Felix Kupprat y Simon Martin por haber realizado comentarios a la versión original de este trabajo y a los revisores anónimos del mismo por sus valiosas observaciones.

\section{Bibliografía}

Baron, Joanne P.

2016 Patron Gods and Patron Lords. The Semiotics of Classic Maya Community Cults. Boulder: University Press of Colorado.

Barrientos, Tomás, Marcello Canuto y Joselyn Ponce

2012 Proyecto Regional Arqueológico La Corona: Informe final, T. Barrientos, M. Canuto y J. Ponce (eds.). Guatemala: Instituto de Antropología e Historia.

Bazy, Damian, Juan Antonio Valdés y Marie Charlotte Arnauld

2010 "El templo doméstico y la casa política: de rituales privados a rituales públicos en centros mayas clásicos”, El ritual en el mundo maya: de lo privado a lo público, pp. 181-201, Andrés Ciudad, María Josefa Iglesias y Miguel Sorroche (eds.). Madrid: Sociedad Española de Estudios Mayas.

Beliaev, Dmitry

2013 Informe del Proyecto Atlas Epigráfico de Petén. Guatemala: Centro de Estudios Mayas Yuri Knórozov.

Berlin, Heinrich

1958 "El glifo emblema en las inscripciones mayas", Journal de la Société des Americanistes, vol. XLVII: 111-119, <http://www.persee.fr/doc/jsa_00379174_1958_num_47_1_1153> [Fecha de consulta: 20 de octubre de 2016]

Boot, Erik

2005 Continuity and Change in Text and Image at Chichén Itzá, Yucatan, México. A Story of the Inscriptions, Iconography, and Architecture at a Late Classic to Early Postclassic Maya Site. Leiden: CNWS Publications.

Boucher, Sylviane

2014 "Vasijas estilo códice de Calakmul. Narraciones mitológicas y contextos arqueológicos", Arqueología Mexicana, 128: 58-65.

Boucher, Sylviane y Yoly Palomo

2012 "Discriminación visual como determinante de estilo y asignación tipológica de la cerámica códice de Calakmul, Campeche”, Estudios de Cultura Maya, 39: 99-132.

Card, Jeb J. y Marc Zender

2016 "A Seventh-Century Inscribed Miniature Flask from Copan found at Ta- 
zumal, El Salvador”, Ancient Mesoamerica, 27: 279-292. DOI: 10.1017/ S0956536116000298.

Carrasco Pizana, Pedro

1996 Estructura político-territorial del Imperio tenochca. La Triple Alianza de Tenochtitlan, Tetzcoco y Tlacopan. México: Fondo de Cultura Económica.

Carrasco Vargas, Ramón y María Cordeiro Baqueiro

2012 "The Murals of Chiik Nahb Structure Sub 1-4, Calakmul, Mexico", Maya Archaeology, 2: 8-59.

Carrasco Vargas, Ramón, Omar Rodríguez Campero, Amalia Enríquez, Veronica A. Vázquez López, Claudia Reyes, Alice D. Desprat, Francisco J. Bernárdez, Irene García, Asunción Terroso, Xian Rodríguez, Vera Tiesler, Patricia Quintana, Iván Oliva y Daniel Aguilar

2005 Proyecto arqueológico Calakmul. Informe técnico, temporada 2005. Tomo I. México: Instituto Nacional de Antropología e Historia.

Cases, Ignacio y Alfonso Lacadena

2015 “Operación III.5: Estudios Epigráficos, Temporada 2014”, Proyecto PeténNorte Naachtún 2010-2014: Informe final de la Quinta Temporada de Campo 2014, pp. 371-384, Phillip Nondédéo et al. (eds.). Guatemala, París: Université Paris 1 Panthéon-Sorbonne, Centre National de la Recherche Scientifique, Centro de Estudios Mexicanos y Centro-Americanos.

Ciudad Ruiz, Andrés y Alfonso Lacadena

2006 "La fundación de Machaquilá, Petén, en el Clásico Tardío maya", Nuevas ciudades, nuevas patrias. Fundación y refundación de ciudades en Mesoamérica y el Mediterráneo Antiguo, pp. 149-180, Ma. Josefa Iglesias Ponce de León, Rogelio Valencia Rivera y Andrés Ciudad Ruiz (eds.). Madrid: Sociedad Española de Estudios Mayas.

García Barrios, Ana y Erik Velásquez García

2010 "Artistas, gobernantes y magos: el papel de los chatan winik en la sociedad maya clásica”, en $15^{a}$ Conferencia Maya Europea. Manuscrito en posesión de los autores.

2016 "Los hombres divinos de Chatahn. Historia y papel social de un 'linaje' maya del Clásico”, Arqueología Mexicana, 139: 80-85.

Garza, Mercedes de la, Guillermo Bernal y Martha Cuevas

2012 Palenque-Lakamha'. Una presencia inmortal del pasado indígena. México: El Colegio de México y Universidad Nacional Autónoma de México.

Grube, Nikolai

2005 "Toponyms, Emblem Glyphs, and the Political Geography of Southern Campeche", Anthropological Notebooks, XI: 89-102.

2008 "Monumentos esculpidos: epigrafía e iconografía", Reconocimiento arqueológico en el sureste del estado de Campeche: 1996-2005, I, pp. 177-231, Ivan Šprajc (ed.). Oxford: Archeopress (BAR International Series 1742). 
Grube, Nikolai y Iken Paap

2005 “Uxul: Petén campechano: primera temporada de campo 2009”, Los Investigadores de la Cultura Maya, 18 (II): 7-24.

Grube, Nikolai, Kai Delvendahl y Nicolaus Seefeld

2012 "Under the Rule of the Snake Kings: Uxul in the 7th and 8th Centuries", Estudios de Cultura Maya, XL: 11-49. DOI: http://dx.doi.org/10.19130/iifl. ecm.2012.40.162.

Hansen, Richard D., Ronald L. Bishop y Federico Fahsen

1991 "Notes on Maya Codex-Style Ceramics from Nakbe, Peten, Guatemala”, Ancient Mesoamerica, 2: 225-243. DOI: https://doi.org/10.1017/S0956536100000547.

Helmke, Christophe y Jaime J. Awe

2016a "Death Becomes Her: An Analysis of Panel 3, Xunantunich, Belize", The PARI Journal, 16 (4): 1-14.

2016b "Sharper than a Serpent's Tooth: A Tale of the Snake-Head Dynasties Recounted on Xunantunich Panel 4", The PARI Journal, 17 (2): 1-22.

Houston, Stephen

1993 Hieroglyphs and History at Dos Pilas. Dynastic Politics of the Classic Maya. Austin: University of Texas Press.

Lacadena, Alfonso

2008 "El título Lakam: evidencia epigráfica sobre la organización tributaria y militar interna de los reinos mayas del Clásico”, Mayab, 20: 23-43.

2016 "Evolución de las fórmulas reverenciales mayas asociadas a los títulos políticos de rango y cargo desde el período Clásico hasta la época colonial”, $10^{\circ}$ Congreso Internacional de Mayistas, Los mayas: discursos e imágenes del poder, del 26 de junio al 2 de julio de 2016, Izamal, Yucatán, México.

Looper, Matthew G.

2007 "The History of Xkuy, An Unidentified Southeastern Center", Glyph Dwellers Report 24, pp. 1-10. Davis: University of California (Maya Hieroglyphic Database Project).

Martin, Simon

1998 Report on Epigraphic Fieldwork at Calakmul: 1995-1998. Documento en posesión del autor.

2005 "De serpientes y murciélagos: Identidades cambiantes en Calakmul”, The PARI Journal, VI (2): 5-15.

En prensa "Reading Calakmul: Recent Epigraphic Finds of the Proyecto Arqueológico Calakmul”, Arqueología, imagen y texto: homenaje a Ian Graham. Memoria de la Sexta Mesa Redonda de Palenque. México: Instituto Nacional de Antropología e Historia.

Martin, Simon y Nikolai Grube

2008 Chronicle of the Maya Kings and Queens: Deciphering the Dynasties of the Ancient Maya. Londres: Thames and Hudson. 
Martin, Simon, Stephen Houston y Marc Zender

2015 "Sculptors and Subjects: Notes on the Incised Text of Calakmul Stela 51", $<$ https://decipherment.wordpress.com/2015/01/07/sculptors-and-subjectsnotes-on-the-incised-text-of-calakmul-stela-51/> [Fecha de consulta: 18 de octubre de 2016]

Martin, Simon y Erik Velásquez García

2016 "Polities and Places: Tracing the Toponyms of the Snake Dynasty", The PARI Journal, 17 (2): 23-33

Mathews, Peter, Kathryn Reese-Taylor, Marcelo Zamora y Alexander Parmington

2005 "Los Monumentos de Naachtun, Péten", XVIII Simposio de Investigaciones Arqueológicas en Guatemala, 2004, pp. 691-696. Guatemala: Museo Nacional de Arqueología y Etnología.

Pincemin, Sophia, Joyce Marcus, Lynda F. Folan, William J. Folan, María del Rosario Domínguez Carrasco y Abel Morales López

1998 "Extending the Calakmul Dynasty Back in Time: A New Stela from a Maya Capital in Campeche, Mexico", Latin American Antiquity: 310-327. DOI: $10.2307 / 3537030$.

Pope, Maurice

1999 The Story of Decipherment. From Egyptian Hieroglyphs to Maya Script. Londres y Nueva York: Thames and Hudson.

Reents-Budet, Dorie, Sylviane Boucher, Yoly Palomo, Ronald Bishop y James Blackman

2010 "Codex Style Ceramics: New Data Concerning Patterns of Production and Distribution”, XXIV Simposio de Investigaciones Arqueológicas en Guatemala. Guatemala: Museo Nacional de Arqueología y Etnología. Maya Vase Database <http://www.mayavase.com/codex.pdf $>$.

Robichaux, Hubert R.

2010 The Ancient Maya Monuments at Oxpemul, Campeche, México. A Report of the Oxpemul Archaeological Project. Campeche: Centro de Investigaciones Históricas y Sociales, Universidad Autónoma de Campeche.

Robichaux, Hubert R. y Candace Pruett

2005 "Las inscripciones de Oxpemul”, Los Investigadores de la Cultura Maya, 13: 29-44.

Ruppert, Karl y John Denison

1943 Archaeological Reconnaissance in Campeche, Quintana Roo, and Petén. Washington: Carnegie Institution of Washington (Publication 543).

Salinas, Alejandra y Rogelio Valencia

2013 "Hallazgos recientes en la estructura XXI de la Gran Acrópolis de Calakmul", XXV Simposio de Investigaciones Arqueológicas en Guatemala, 2012. B. Arroyo, 
A. Linares y L. Paiz (eds.), pp. 101-112. Guatemala: Museo Nacional de Arqueología y Etnología.

Santamarina Novillo, Carlos

1998 "La muerte de Chimalpopoca. Evidencias a favor de la tesis golpista", Estudios de Cultura Náhuatl, 28: 277-316.

Sheseña Hernández, Alejandro

2015 Joyaj ti 'ajawlel. La ascensión al poder entre los mayas clásicos. Tuxtla Gutiérrez: Editorial Afínita, Universidad de Ciencias y Artes de Chiapas.

Stone, Andrea y Marc Zender

2005 Reading Maya Art. A Hieroglyphic Guide to Ancient Maya Painting and Sculpture. Londres: Thames and Hudson.

Stuart, David

1992 The Lakam Sign, manuscrito en posesión del autor.

2012 Notes on a new text from La Corona, <http://decipherment.wordpress. com/2012/06/30/notes-on-a-new-text-from-la-corona/> [Fecha de consulta: 20 de octubre de 2016].

2013 Name and Image on Two Codex-style Vessels, <http://decipherment.wordpress. com/2013/08/21/report-name-and-image-on-two-codex-style-vessels/> [Fecha de consulta: 20 de octubre de 2016].

Stuart, David y Joan Baron

2012 "Análisis preliminar de las inscripciones de la Escalinata Jeroglífica 2 de La Corona", Proyecto Regional Arqueológico La Corona: Informe final, pp. 187-220, T. Barrientos, M. Canuto y J. Ponce (eds.). Guatemala: Instituto de Antropología e Historia.

Thompson, Eric S.

1962 A Catalog of Maya Hieroglyphs. Oklahoma: University of Oklahoma Press.

Tsukamoto, Kenichiro

2014 "Politics in Plazas: Classic Maya Ritual Performance at El Palmar, Campeche, Mexico", tesis de doctorado en Filosofía. Tucson: The University of Arizona.

Tsukamoto, Kenichiro y Octavio Q. Esparza Olguín

2015 "Ajpach' Waal: The Hieroglyphic Stairway of the Guzmán Group of El Palmar, Campeche, Mexico", Maya Archaeology, 3: 30-55.

Tunesi, Raphael

2007 "A New Monument Mentioning Wamaaw K'awiil of Calakmul", The PARI Journal, 8 (2): 13-19, <www.mesoweb.com/pari/publications/journal/802/ Tunesi-2007.pdf $>$ [Fecha de consulta: 20 de octubre de 2016].

Valencia Rivera, Rogelio, Albert Davletshin, Hugo García Capistrán, Felix Kupprat y Verónica A. Vázquez López

2014 "Leyendo una estela: el contexto arqueológico, el texto y la imagen de la Es- 
tela 43 de Calakmul”, ponencia presentada en las 2as. Jornadas Académicas Sistemas de Escritura Mesoamericanos. Estado de la cuestión y problemas actuales. México: Universidad Nacional Autónoma de México.

Valencia Rivera, Rogelio y Octavio Q. Esparza Olguín

2014 "La conformación política de Calakmul durante el Clásico Temprano", Arqueología Mexicana, 128: 36-40.

Valencia Rivera, Rogelio, Ramón Carrasco Vargas y María Cordeiro Baqueiro

En prensa "Los mascarones de la Gran Plaza de la ciudad de Calakmul", Mexicon.

Vázquez López, Verónica A., Felix Kupprat, Carlos Morales Aguilar, Hugo García Capistrán y Rogelio Valencia Rivera

2015 "Los cambios de poder en el juego interdinástico: los gobernantes de Calakmul de los siglos V al VIII d.C.”, XXIX Simposio de Investigaciones Arqueológicas en Guatemala, pp. 1101-1114, Bárbara Arroyo, Luis Méndez Salinas y Gloria Ajú Álvarez (eds.). Guatemala: Museo Nacional de Arqueología y Etnología.

Velásquez García, Erik

2008 "Los posibles alcances territoriales de la influencia política de Dzibanché durante el Clásico Temprano: nuevas alternativas para interpretar menciones históricas sobre la entidad política de Kan”, El territorio maya. Memoria de la Quinta Mesa Redonda de Palenque, pp. 323-352, Rodrigo Liendo (ed.). México: Instituto Nacional de Antropología e Historia.

En prensa "En busca de Testigo Cielo (ca. 561-572 d.C.): el punzón de hueso del Edificio de los Cormoranes de Dzibanché", Arqueología, imagen y texto: homenaje a Ian Graham. Memoria de la Sexta Mesa Redonda de Palenque. México: Instituto Nacional de Antropología e Historia. 


\section{Apéndice 1}

Ejemplos del GE del murciélago presentes en las inscripciones de Copán y Quiriguá.

\begin{tabular}{|c|c|c|}
\hline \multirow{18}{*}{$\begin{array}{l}\text { Signos iconográficos } \\
\text { de piedra }\end{array}$} & Copán & Altar Estela 5 \\
\hline & Copán & Altar Estela R \\
\hline & Copán & Altar Estela T \\
\hline & Copán & Altar Estela U \\
\hline & Copán & Altar Estela W \\
\hline & Copán & Altar Estela Z \\
\hline & Copán & Vaso de alabastro de El Abra \\
\hline & Copán & Estela 2 \\
\hline & Copán & Estela 6 \\
\hline & Copán & Estela 7 \\
\hline & Copán & Estela 8 \\
\hline & Copán & Estela 9 \\
\hline & Copán & Estela M \\
\hline & Copán & Texto Estructura 12 \\
\hline & Copán & Espina de mantarraya \\
\hline & Copán & Inscripción Templo 11 \\
\hline & Copán & Banqueta Estructura 9N-82 \\
\hline & Quiriguá & Altar L \\
\hline
\end{tabular}




\begin{tabular}{|c|c|c|}
\hline \multirow{17}{*}{$\begin{array}{l}\text { Signos iconográficos } \\
\text { de piedra y silaba -pi }\end{array}$} & Copán & Estela A \\
\hline & Copán & Estela I \\
\hline & Copán & Estela N \\
\hline & Copán & Base de la Estela $\mathrm{N}$ \\
\hline & Copán & Estela 10 \\
\hline & Copán & Estela 12 \\
\hline & Copán & Estela 1 \\
\hline & Copán & Estela P \\
\hline & Copán & Vaso K3296 \\
\hline & Copán & Altar Estela I \\
\hline & Copán & Altar Estela $\mathrm{K}$ \\
\hline & Quiriguá & Altar O \\
\hline & Quiriguá & Altar P' \\
\hline & Quiriguá & Estela E \\
\hline & Quiriguá & Texto Estructura 1B \\
\hline & Quiriguá & Zoomorfo G \\
\hline & Quiriguá & Zoomorfo P \\
\hline $\begin{array}{l}\text { Signos iconográficos } \\
\text { de piedra y silaba -pu }\end{array}$ & Copán & Estela 11 \\
\hline \multirow{3}{*}{ Sílaba -pi } & Copán & Banqueta Templo 21 \\
\hline & Copán & Cráneo de pecarí \\
\hline & Copán & $\begin{array}{l}\text { Escalera Jeroglífica-registro } \\
\text { de ascensión de Yax K'uk' Mo' }\end{array}$ \\
\hline \multirow{2}{*}{ Sílaba -pu } & Copán & Escalón Estructura 10L-11 sub \\
\hline & Copán & Estela 49 \\
\hline Silaba -pi y sílaba -pu & Copán & Estela Papagayo \\
\hline \multirow{3}{*}{ Otros } & Copán & $\begin{array}{l}\text { Xukpi Stone. Ak'ab infijo en nariz y } \\
\text { mejilla }\end{array}$ \\
\hline & Copán & $\begin{array}{l}\text { Banqueta Estructura } 9 \mathrm{~N}-158 \text {. } \\
\text { No se distingue complemento alguno }\end{array}$ \\
\hline & Copán & Vasija de Tazumal. Punto en la mejilla \\
\hline
\end{tabular}


